In the March number of "Anales del Circulo Medico Argentino," Dr. Lucio Melendez draws attention to the frequency of this affection in his country, and makes a comparison between it and beri-beri.

"Beri-beri is endemic in India and the warm countries of South America. All cases occurring in our country are due not to spontaneous generation, but to transportation.

Beri-beri is considered by many as infectious. Malignant hydrops, although of a similar nature, is not quite so infectious.

Beri-beri affects all, without distinction to color, race, temperament, or preëxisting disease. Malignant hydrops attacks exclusively the insane, and especially the chronic demented, and filthy.

In beri-beri we meet varieties with paralysis.

In hydrops paralysis is never noted.

In beri-beri disturbances of the gastro-intestinal tract are of frequent occurrence.

In hydrops there is neither emesis nor diarrhoa; the appetite is preserved, the tongue is clean and moist, and the bowels are prone to constipation.

In beri-beri the progress is rapid and fulminating.

In hydrops the progress is slow, never fulminating.

Beri-beri attacks many persons in a short space of time.

In hydrops I have seen but eight to ten persons per month in an epidemic which lasted five months." W.C.K.

\title{
MULTIPLE SCLEROSIS IN CHIIDREN AND ITS
}

RELATION TO ACUTE INFECTIOUS DISEASES.

The "Kinder-Arzt," of June, contains an abstract of a paper published by A. Nolda, in the "Correspbl. f. Schweizer Arzte," No. 5, I891, on the above subject. Twenty years ago, according to the author, multiple sclerosis had never been observed in childhood. Schule, P. Marie, L. Unger and Ebstein then published cases of the disease in children. Later, Ebstein and Westphal described cases in which the affection followed infectious diseases of various kinds and Marie even asserted that infectious disease was the cause of the malady.

Unger, in studying the etiology of multiple sclerosis as seen in childhood, concluded from his observations that preceding diseases, especially those of an infectious nature, were a very important factor in its causation. 
Of the seven cases observed by Nolda, in six there was a history of previous infectious disease-diphtheria in three cases, scarlet fever in two cases, and pneumonia in one case-and in five of these cases the symptoms of multiple sclerosis followed immediately upon the infectious disease in question. In the sixth case the symptoms of the nervous affection developed some months after the preceding malady. We must therefore conclude from these observations of Nolda, that multiple sclerosis is to be regarded as a sequela of acute infectious diseases. Adamkiewicz has shown that the lesion in multiple sclerosis consists of a primary affection of the nerves of the central nervous system, with secondary change of the neuroglia. Hence, Nolda assumes that the virus of.the infectious disease penetrates in some unknown way the medullary sheaths of the central nervous system, which apparently are especially sensitive to it, and thence sets up the whole process.

According to Marie, multiple sclerosis occurs more often in children than has hitherto been accepted and $\mathrm{K}$. Oppenheim asserts that the disease in the adult can not so very rarely be traced back to the earliest childhood. J. W. B.

CI,INICAL.

\section{TABES DORSALIS COMBINED WITH MUSCULAR ATROPHY.}

Jolly recently showed to the Berlin Society of Psychiatria and Nervous Diseases, a case of combined tabes dorsalis and muscular atrophy with paresis. The "Centralblatt für Nervenheilkunde and Psychiatrie," for June, gives some details of the case. The patient was a woman, fifty-one years of age, who, seven years previously had had diplopia and vertigo. For the past four years she has had a furry feeling in the soles of the feet, and of late unpleasant sensations, first in the left hand and then in the right hand also. Syphilis was denied, but the patient had had several miscarriages. She had been often exposed to wet weather and had been obliged to carry very heavy loads.

Status præsens : Ataxia both on standing and on walking, also a paralysis of the left peroneal muscles. The dorsal flexion of the toes of the left foot is affected, while in the right foot the movements are normal. The test for sensibility gives varying results. A light touch is not felt by the great toes of either foot, but sensation to pain is present. The muscular sense of the great toes is also affected. 